\title{
Involvement of S100A8/A9-TLR4-NLRP3 Inflammasome Pathway in Contrast- Induced Acute Kidney Injury
}

\author{
Xuexian Tan ${ }^{\mathrm{a}} \quad$ Xiaohe Zheng $^{\mathrm{b}}$ Zena Huang ${ }^{c}$ Jiaqiong Lin ${ }^{\mathrm{d}}$ Chuli Xie Yan Lin $^{f}$ \\ aDepartment of Pathology, Third Affiliated Hospital, Guangzhou Medical University, Guangzhou, \\ ${ }^{b}$ Clinical Laboratory, First Affiliated Hospital, Sun Yat-sen University, Guangzhou, 'Department of \\ Critical Care Medicine and Emergency, Guangdong General Hospital, Guangdong Academy of Medical \\ Sciences, Guangzhou, dDepartment of Medical Genetics, School of Basic Medical Sciences, Southern \\ Medical University, Guangzhou, eDepartment of Physiology, Zhongshan School of Medicine, SunYat- \\ sen University, Guangzhou, 'Department of Nephrology, Third Affiliated Hospital, Guangzhou Medical \\ University, Guangzhou, China
}

\section{Key Words}

S100A8/A9 • TLR4 • NLRP3 inflammasome • Contrast medium • Acute kidney injury

\begin{abstract}
Background: Contrast-induced acute kidney injury (CIAKI) is a common cause of hospitalacquired acute kidney injury (AKI). S100A8/A9-TLR4-NLRP3 inflammasome pathway triggers inflammation, apoptosis and tissue injury in several AKI models. Nevertheless, the underlying mechanism of S100A8/A9-TLR4-NLRP3 inflammasome pathway in CIKAI is not clear. We aimed to investigate the possible role of S100A8/A9-TLR4-NLRP3 inflammasome in the pathophysiology of CIAKI. Methods: We treated male rats and NRK-52E cells by iopromide to establish in vivo and in vitro models of CIAKI. We collected serum and urine samples to detect renal function. We obtained kidney tissue for histological analysis and detection of protein concentration. We used inhibitor of TLR4 and NLRP3-siRNA to further testify their role in CIAKI in NRK-52E cells. Results: Iopromide caused elevation of SCr, BUN and NGAL level, decrease of endogenous creatinine clearance, morphological injury and tubular apoptosis, enhanced IL-1 $\beta$ and IL-18 expression, and increased expression of S100A8/A9, TLR4 and NLRP3 inflammsome. In NRK-52E cells, iopromide caused enhanced apoptotic rates and ROS generation, which could be ameliorated by inhibitor of TLR4 and NLRP3-siRNA. Moreover, inhibition of TLR4 dampened NLRP3 expression. Conclusion: S100A8/A9-TLR4-NLRP3 inflammasome pathway represented a key mechanism of CI-AKI, which provided a potential therapeutic target.
\end{abstract}




\section{Introduction}

Contrast-induced acute kidney injury (CIAKI) is an important syndrome of acute renal failure occurring after the intravascular administration of iodinated contrast media (CM) in diagnostic and interventional procedures. CIAKI is the third most common cause of acute renal failure in hospitalized patients [1], accounting for up to $12 \%$ of all cases of acute renal failure $[2,3]$. CIAKI is also associated with replacement therapy, prolonged hospitalization, increased medical cost and increased mortality $[4,5]$. The factors contributed to the pathophysiology of CIAKI are still under controversy, but primarily involve the tubular toxicity, microvascular alteration, oxidative stress, inflammation and tubular obstruction [4, 6-8]. Among these factors, inflammatory damage may be regarded as one of the most crucial factors in the development of CIAKI. Hence, studies on the mechanism of inflammatory damage induced by CM may be crucial to formulate innovative prevention and treatment programs.

S100A8 (also termed MRP8) and S100A9 (MRP14) are calcium-binding secretory proteins that can form homodimers and heterodimers, with the latter being more prevalent $[9,10]$. The heterodimer S100A8/A9, derived from neutrophils and monocytes; acts as activator of the innate immune system [11]. In several studies of acute kidney injury (AKI), S100A8/A9 expression was significantly elevated, parallel to the extent of kidney injury. In a model of unilateral ureteral obstruction, S100A8/A9 was markedly produced by epithelial cells of renal collecting duct [12]. Moreover, S100A8/A9 was also induced in response to ischemic reperfusion injury in mice [13]. However, the role and mechanisms of S100A8/A9 in CIAKI have not yet been reported.

S100A8 and S100A9 have been noted to be endogenous activators of Toll-like receptor 4 (TLR4) [14]. TLR4, as one of the signal transduction receptors in pattern recognition receptor, plays an important role in noninfectious inflammatory diseases [15]. Emerging studies described that TLR4-mediated inflammatory response facilitate renal injuries, especially acute kidney injury $[16,17]$. For example, an increased TLR-4 expression was noted in kidneys with ischemia-reperfusion, accompanied with significantly increase of chemokines [18]. Furthermore, in TLR4-deficient mice, less interstitial neutrophil and tubular damage were observed [19]. Therefore, TLR4 may also play an important role in CIAKI.

The nucleotide-binding domain, leucine-rich-containing family, pyrin domaincontaining-3 (NLRP3) inflammasome has emerged as an important regulator of inflammation [20]. It consists of apoptosis-associated speck-like protein containing a caspase recruitment domain (ASC) and caspase-1. In vivo study showed that NLRP3 inflammasome-knockout mice developed low expression of inflammatory cytokines and less damage in the kidney compared with wild-type mice [21]. In addition, NLRP3 was validated to have a profound effect on renal function in a kidney ischemia model [22]. In various renal diseases, TLR4 was confirmed to induce NLRP3 inflammasome activation and hence promote kidney injury [2325]. Although significant effect of NLRP3 inflammasome has been characterized in various renal diseases [26-28], its role in CNAKI remains unclear.

Hence, in the present study, we sought to determine whether S100A8/A9 proteins contribute to the CIAKI via activation of TLR4/NLRP3 inflammasome pathway, in both in vivo and in vitro models. To our knowledge, we have investigated for the first time about the role and mechanism of S100A8/A9 in CIAKI.

\section{Materials and Methods}

\section{Material}

The iodinated radiographic contrast agent used in this study, iopromide (Ultravist 370; $370 \mathrm{mg} /$ ml iodine) was purchased from Bayer HealthCare LLC (Leverkusen, Germany). Indomethacin, N-nitro-Larginine methyl ester, Hoechst 33258 and 2', 7'-dichlorofluorescein diacetate (DCFH-DA) were obtained from Sigma-Aldrich (St. Louis, MO, USA). The TUNEL detecting kit was bought from Roche (Mannheim, Germany) and the 4'-6-diamidino-2-phenylindole (DAPI) was obtained from Vector (Burlingame, CA, 
USA). Anti-TLR4, Anti-NLRP3 and Anti-ASC antibody were purchased from Abcam Inc. (Cambridge, MA, USA); Anti-Caspase-1 and Anti-Caspase-3 were obtained from Cell Signaling Technology (Beverly, MA, USA); Anti-GAPDH, horseradish peroxidase (HRP)-conjugated goat anti-rabbit secondary antibody, HRPconjugated donkey anti-goat secondary antibody and HRP-conjugated goat anti-mouse secondary antibody were purchased from Proteintech Group, Inc. (Wuhan, China). Dulbecco's modified Eagle's medium (DMEM) medium and fetal bovine serum (FBS) were purchased from Gibco BRL (Grand Island, NY, USA). BCA protein quantification kit was obtained from KangChen Bio-tech (Shanghai, China). The enhanced chemiluminescence (ECL) solution was purchased from KeyGen Biotech (Nanjing, China). The Cell Counting Kit-8 (CCK-8) was offered by Dojindo Laboratories (Kumamoto, Japan). NGAL, IL-1 $\beta$ and IL-18 ELISA kits were purchased from Cusabio Biotech Co. Ltd (Wuhan, China). S100A8/A9 ELISA kit was obtained from Jiang Lai Biotech Co. Ltd (Shanghai ,China). Total protein extraction kit was purchased from (Invent Biotech Inc (Edenprairie, MN, USA). TAK-242 (inhibitor of TLR4) and Lipofectamine transfection reagent was supplied by Life Tech (Carlsbad, CA, USA). Si-RNA of NLRP3 was purchased from Ribobio Biotech (Guangzhou, China). The NRK-52e cells were supplied by Jiniou company (Guangzhou, China).

\section{Animal studies}

CIAKI in rats. All animal experiments were conducted in accordance with the guidelines of Guangzhou Medical University for the care and use of laboratory animals. Mature male Sprague-Dawley rats, weighing 180-200 $\mathrm{g}$ at the start of the experiment, were housed in individual cages under controlled conditions of light $\left(12 \mathrm{~h} / 12 \mathrm{~h}\right.$ light/dark cycle) and temperature $\left(21-23^{\circ} \mathrm{C}\right)$ and allowed free access to standard laboratory diet and tap water. After a 7-day period of acclimatization to the experimental area, rats were subjected to the previously detailed CIAKI protocol [29, 30], consisting of indomethacin $(10 \mathrm{mg} / \mathrm{kg})$, followed at 15 and $30 \mathrm{~min}$, respectively, by N-nitro-L-arginine methyl ester $(10 \mathrm{mg} / \mathrm{kg})$ and iopromide $(2.9 \mathrm{~g} / \mathrm{kg})$. Controls were obtained by injections of saline alone administered at each time point. All drugs were injected through the tail vein. The rats were allowed to recover in metabolic cages for an additional $48 \mathrm{~h}$, and urine samples were collected and used for the determination of urinary creatinine excretion. After the rat body mass was obtained and the blood samples were collected for the determination of serum creatinine ( $\mathrm{SCr}$ ), blood urea nitrogen (BUN) and neutrophil gelatinase-associated lipocalin (NGAL), the rats were killed under diethyl ether anesthesia. The kidneys were removed, weighted and bisected in the equatorial plane; the right kidney was divided for western blot analyses, and the left kidney was fixed in phosphate-buffered $4 \%$ formalin and prepared for routine histological examination.

Biochemical evaluation of blood and urine samples. Mean SCr, BUN and urinary creatinine (UCr) concentrations were measured using automatic biochemistry analyzer at the Clinical Laboratory, The First Affiliated Hospital of Sun Yat-sen University. The concentrations of NGAL, IL-1 $\beta$, IL-18 and S100A8/A9 were determined by ELISA. Glomerular filtration rate was estimated from endogenous creatinine clearance (ClCr) using the standard formula: $\mathrm{ClCr}=\mathrm{UCr} \times$ urine volume/SCr. Creatinine clearance for 24 and $48 \mathrm{~h}$ after the injection of contrast medium was calculated as $\mathrm{ml} / \mathrm{min}$.

Histological examination of renal tissues. The left kidney fixed in $4 \%$ formalin was dehydrated in a graded series of ethyl alcohol and embedded in paraffin. Kidney blocks cut into $4-\mu \mathrm{m}$ sections were subjected to hematoxylin and eosin (HE) staining and PAS staining for morphologic analysis. HE-stained and PASstained tissue sections were viewed by light microscopy at 200 or 400 magnification. For semiquantitative analysis of morphological changes, 10 high-magnification $(\times 200)$ fields of the cortex and outer stripe of the outer medulla were randomly selected from HE-stained sections. The abnormal tubular histopathology was scored and graded by a semi-quantitative score from 0 to 4 points, according to Weidemann's study [31]: 0 , no abnormalities; $1+$, changes affecting less than $25 \%$ of the sample; $2+$, changes affecting $25-50 \%$; $3+$, changes affecting $50-75 \%$; $4+$, changes affecting more than $75 \%$. All quantifications were performed in a blinded manner.

To detect apoptotic DNA fragmentation, TUNEL assay was performed on paraffin-embedded kidney tissue with an in situ cell death detection kit. Sections were counterstained with DAPI. After fluorescein staining, the TUNEL positive cells appeared brightly green in color under a fluorescent microscope.

Western blot analysis. Nuclear and cytoplasmic proteins from kidney tissues were extracted and protein concentration was determined. Equal amount of protein $(40 \mu \mathrm{g}$ ) were separated by $12 \%$ SDS-PAGE and transferred to $0.45 \mu \mathrm{m}$ polyvinylidene fluoride membranes. The membranes were blocked for $2 \mathrm{~h}$ with $5 \%$ nonfat dry milk at room temperature. Then, the membranes were incubated with primary antibodies 


\section{Cellular Physiology Cell Physiol Biochem 2017;43:209-222 \begin{tabular}{ll|l} 
and Biochemistry 10.1159/000480340 & $\begin{array}{l}\text { C } 2017 \text { The Author(s). Published by S. Karger AG, Basel } \\
\text { www.karger.com/cpb }\end{array}$ \\
\hline
\end{tabular}}

Tan et al.: S100A8/A9 Pathway in CIAKI

specific to TLR4 (1:1000), NLRP3 (1:1000), ASC (1:500), Caspase-1 (1:1000), Caspase-3 (1:1000) or GAPDH (1:10000) overnight at $4{ }^{\circ} \mathrm{C}$. After washing three times, the membranes were probed with the secondary antibody (1:5000) at room temperature for $1 \mathrm{~h}$. Blots were then developed with the ECL Plus Western Blotting Detection System (Amersham Life Science, UK). Band intensities were quantified using Image J 1.47i software.

\section{In vitro studies}

Cell culture and treatments. NRK-52e cells, were maintained in DMEM and supplemented with 10\% FBS in a humidified incubator with $95 \%$ air and 5\% CO2 at $37{ }^{\circ} \mathrm{C}$. The culture medium was replaced with fresh medium every 2-3 days. When the cells grew to about $80 \%$ confluency, they were expanded to new culture plates. In order to determine the effect of on iodinated contrast media-induced injury, the cells were co-processed with CM for specific durations. To investigate the role of TLR4 in CM-induced injuries in NRK52e cells, $5 \mu \mathrm{M}$ TAK-242 (inhibitor of TLR4) was co-treated with CM.

RNAinterference. NRK-52e cellswere transfected at 70\% confluence usingtransfection reagent, and siRNA against NLRP3 (sense, $5^{\prime}$-GCUUCAGCCACAUGACUUUTT - $3^{\prime}$, and antisense, $5^{\prime}$-AAAGUCAUGUGGCUGAAGCTT $-3^{\prime}$ ) or a physiologically irrelevant negative control siRNA (sense, 5'-UUCUCCGAACGUGUCACGUTT-3', and antisense, 5'-ACGUGACACGUUCGGAGAATT-3'). Each dried-down siRNA was dissolved in nuclease-free water to achieve a final concentration of $20 \mu \mathrm{M}$. Then $5 \mu \mathrm{l}$ siRNA $(20 \mu \mathrm{M})$ and $5 \mu \mathrm{l}$ Lipofectamine were added to a $500 \mu$ l buffer system. The mixes were kept at room temperature for $30 \mathrm{~min}$ to form complexes, and equal aliquots were then added into one of the wells of a 6 -well plate. The cultures were incubated at $37{ }^{\circ} \mathrm{C}$ in a $5 \%$ $\mathrm{CO}_{2}$ incubator. The medium was replaced after $12 \mathrm{~h}$ with DMEM that did not contain either a siRNA or the transfection reagent. Cells were collected at $3 \mathrm{~h}$ for analyses.

Cell viability assay. The CCK-8 assay was applied to detect the viability of the cells. The NRK-52e cells were digested and seeded in 96-well growth-medium plate at a concentration of $1 \times 104$ cells $/ \mathrm{ml}$ and incubated at $37{ }^{\circ} \mathrm{C}$. After the indicated treatments, the cells were washed twice with PBS. Then $10 \mu \mathrm{lCCK}-8$ test solution and $90 \mu \mathrm{l}$ DMEM were added to each well, and the cells were incubated at $37{ }^{\circ} \mathrm{C}$ for $2 \mathrm{~h}$. The absorbance value (OD value) at the $450 \mathrm{~nm}$ wavelength was measured using a microplate reader (Molecular Devices, Sunnyvale, CA, USA). The means of the optical density (OD) of 3 wells in the indicated groups were used to calculate the percentage of cellular activity according to the following formula: cell viability (\%) = (OD treatment group/OD control group) $\times 100 \%$.

Western blot analysis. After indicated treatments, NRK-52e cells were harvested and lysed with RIPA buffer containing $1 \mathrm{mM}$ phenylmethanesulfonyl fluoride (PMSF) at $4{ }^{\circ} \mathrm{C}$ for $30 \mathrm{~min}$. Protein concentration was then determined. Loading buffer was added to the cytosolic extracts and after boiling for approximately 5 min, equal amounts of supernatant from each sample were loaded on $10 \%$ sodium dodecyl sulphatepolyacrylamide gel electrophoresis (SDS-PAGE). The separated proteins were transferred onto polyvinylidene difluoride (PVDF) membranes followed by blocking of the membranes with fresh blocking buffer [0.1\% Tween-20 in Tris-buffered saline (TBS-T) containing 5\% fat-free milk] for approximately 90 min at room temperature. Then the membranes were incubated with primary antibodies specific to TLR4 (1:1000), NLRP3 (1:1000), ASC (1:500), Caspase-1 (1:1000), Caspase-3 (1:1000) or GAPDH (1:10000) in freshly prepared TBS-T with 3\% fat-free milk overnight with slow agitation at $4{ }^{\circ} \mathrm{C}$ temperature. After 3 washes with TBS-T, the membranes were incubated with secondary antibody (1:5000) in TBS-T with 3\% fatfree milk for $60 \mathrm{~min}$ at room temperature. Then the membranes were washed 3 times with TBS-T solution for $15 \mathrm{~min}$. The immunoreactive signals were visualized by ECL detection. In order to quantify the protein expression, the X-ray films were scanned and analyzed with Image J 1.47i software.

Measurement of the secretion of $I L-1 \beta$ and IL-18 by ELISA. The NRK-52e cells were seeded in 96-well growth-medium plates. After indicated treatments, the levels of IL-1 $\beta$ and IL-18 in the culture supernatant were evaluated by ELISA.

Measurement of intracellular ROS level. The intracellular level of ROS was detected using the redoxsensitive fluorescent dye DCFH-DA. Briefly, the culture medium was removed and the cells were washed 3 times with PBS. The cells were incubated with DCFH-DA $(10 \mu \mathrm{M})$ which was diluted by serum-free medium at $37{ }^{\circ} \mathrm{C}$ for $30 \mathrm{~min}$. The cells were then washed 5 times with PBS and the relative amount of fluorescent product was captured using a fluorescence microscope connected to an imaging system (BX50-FLA; Olympus). ImageJ $1.47 \mathrm{i}$ software was apply to analyze the mean fluorescence intensity (MFI) of DCFH-DA, which indirectly showed the level of ROS. 


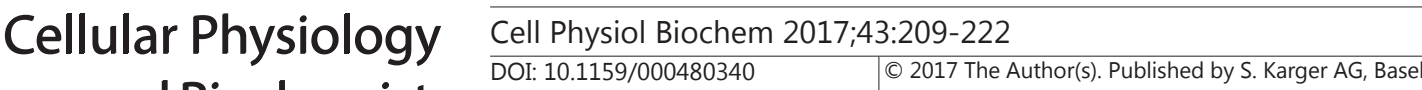

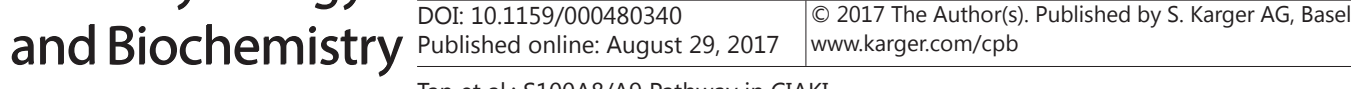

Statistical analysis.

In animal studies, six animals were randomly selected from each group for analysis. In vitro studies, each experiment was repeated 3 times. All datas are expressed as the means \pm SEM. Differences between groups are determined by one-way analysis of variance (ANOVA) using SPSS 13.0 software (SPSS, Inc, Chicago, IL, USA) followed by the least significant difference (LSD) post hoc comparison test. Differences are considered statistically significant at P-value $<0.05$.

\section{Results}

\section{Iopromide caused renal dysfunction in rat CIAKI model}

The rat model of CIAKI was induced by administration of iopromide after the inhibition of prostaglandin and nitric oxide synthesis. As shown in Fig. 1, rats in CIAKI group exhibited elevations in plasma biomarkers of SCr, BUN, and NGAL compared with the control group $24 \mathrm{~h}$ after iopromide injection $(p<0.01)$. Meanwhile, the $\mathrm{ClCr}$ decreased more than $50 \%$ in at $24 \mathrm{~h}$ after iopromide treatment $(p<0.01)$. At $48 \mathrm{~h}$ after iopromide injection, we observed amelioration of $\mathrm{SCr}$, BUN, and NGAL expression, with recovering $\mathrm{ClCr}$.

\section{Iopromide induced morphological alteration in rat CIAKI model}

There were tubular vacuolization and degeneration, necrosis, and hyaline or cellular casts associated with infiltration of mononuclear cells in the contrast medium-treated rats, as determined by HE staining, PAS staining and a semiquantitative scoring analysis of the kidneys $(p<0.01$, Fig. 2A-B). Specifically, the most severe and pronounced alterations were observed in the renal cortico-medullary boundary zone (the cortex and outer stripe of the outer medulla) rather than in the inner stripe of the outer medulla or inner medulla, notably at $24 \mathrm{~h}$ after contrast medium injection. Moreover, the kidney weight to body weight ratios $(\mathrm{Kw} / \mathrm{Bw})$ were markedly elevated in CIAKI groups ( $p<0.01$, Fig. $2 \mathrm{C}$ ), both at $24 \mathrm{~h}$ and $48 \mathrm{~h}$ after iopromide treatment.

\section{Iopromide enhanced tubular apoptosis and inflammation in rat CIAKI model}

We then used TUNEL staining to detect tubular apoptosis. The kidneys from CIAKI group showed a marked increase in the number of TUNEL-positive tubular cells, which was more severe at $24 \mathrm{~h}$ after iopromide treatment than that at $48 \mathrm{~h}$ (Fig. 3A). Western blot

Fig. 1. Iopromide caused renal dysfunction in rat CIAKI model. In CIAKI groups, rats were i.v. injected with iopromide $(2.9 \mathrm{~g} /$ $\mathrm{kg}$ ). In control groups, rats were i.v. injected with saline of the same volume. Changes in the levels of SCr (A), BUN (B), NGAL (D) and ClCr (D) were evaluated at 24 and $48 \mathrm{~h}$ after intravenous injection of iopromide. Each column represents the mean \pm SD $(n=6) .{ }^{* *} \mathrm{p}<0.01$ vs. control.

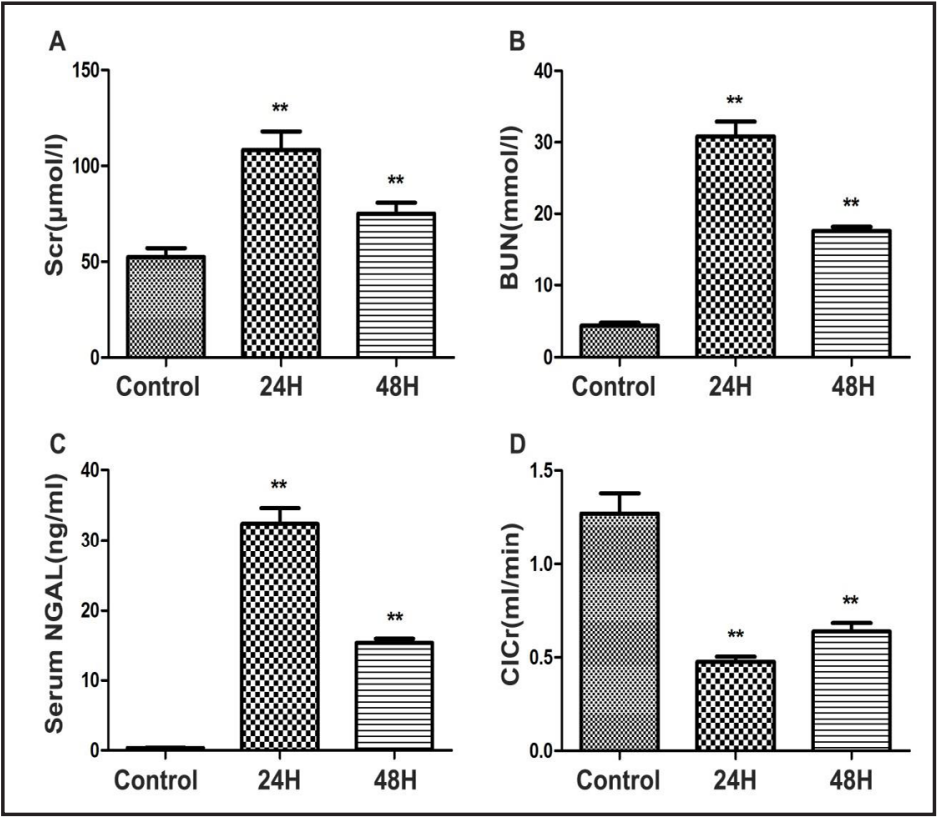




\section{Cellular Physiology Cell Physiol Biochem 2017;43:209-222

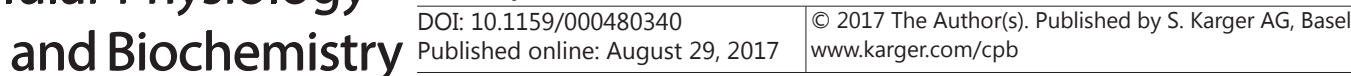

Fig. 2. Iopromide induced morphological alteration in rat CIAKI model. Representative photomicrographs of HE stained kidney sections (Aa-f), PASstained kidney sections (Ag-l) and semiquantitative scoring analysis of tubular degeneration were presented (B). The $\mathrm{Kw} / \mathrm{Bw}$ was elevated at 24 and $48 \mathrm{~h}$ after iopromide injection (C). (Aa, Ad, $\mathrm{Ag}$ and $\mathrm{Aj})$ control rats, $(\mathrm{Ab}, \mathrm{Ae}, \mathrm{Ah}$ and $\mathrm{Ak}$ ) rats at $24 \mathrm{~h}$ after iopromide injection, (Ac, Af, $\mathrm{Ai}$ and $\mathrm{Al}$ ) rats at $48 \mathrm{~h}$ after iopromide injection. Marked tubular vacuolization and degeneration, necrosis, and hyaline or cellular casts associated with infiltration of mononuclear cells were shown. Iopromide caused more severe tubular injuries at $24 \mathrm{~h}$ after iopromide injection than that at $48 \mathrm{~h}$. For the semiquantitative analysis of morphological changes, 10 high magnification $(\times 200)$ fields of the cortex and the outer stripe of the outer medulla in rats were randomly selected. The extent of tubular injury was then graded with a score from 0 to 4 points. Original magnifications: $\times 200$ (Aac and Ag-i); $\times 400$ (Ad-f and Aj-l). Data are presented as mean \pm SD $(n=6) .{ }^{* *} \mathrm{p}<0.01$ vs. control.

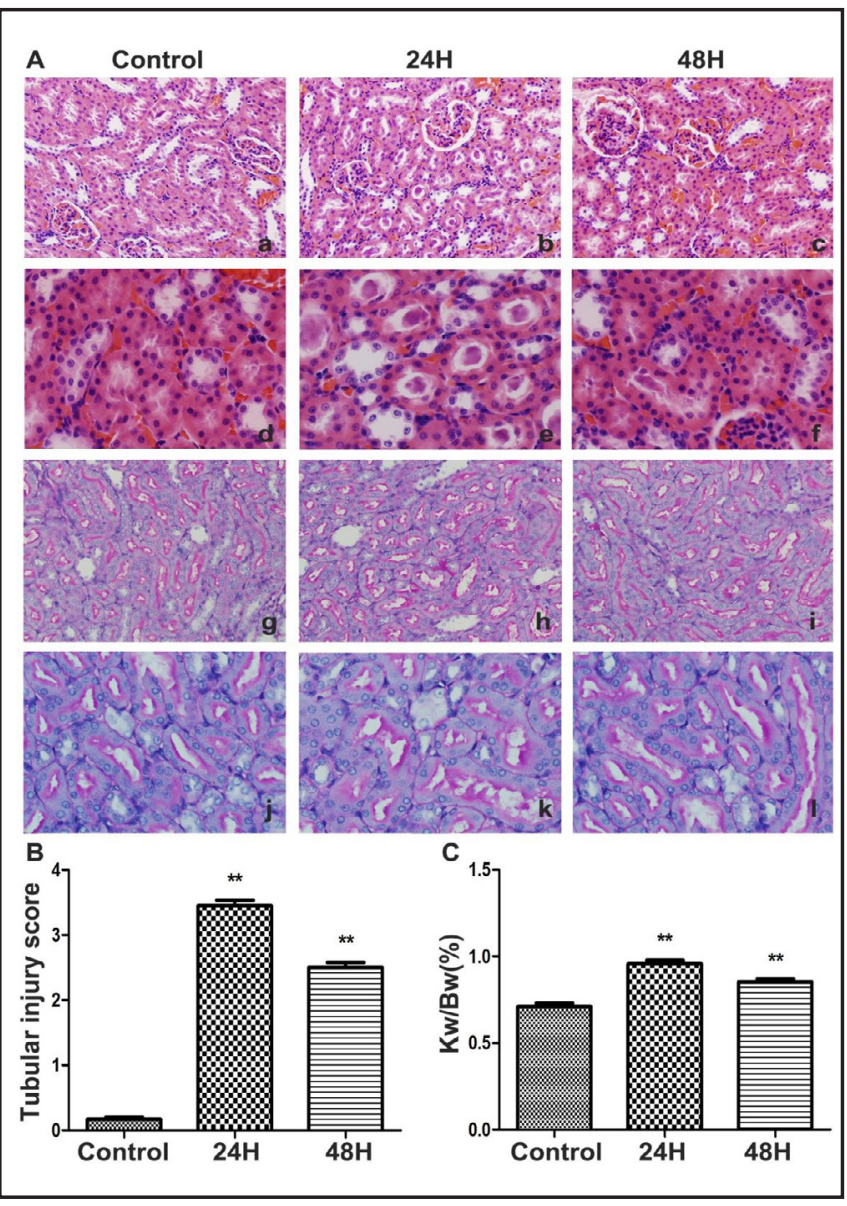

analysis of Caspase-3 was also performed. As presented in Fig. 3B, iopromide induced almost doubled expression of Caspase- 3 compared with control group $(p<0.05)$. Furthermore, we investigated the plasma concentrations of two pro-inflammatory cytokines, IL-1 $\beta$ and IL-18, by ELISA. We found that the iopromide treated rats secreted more IL- $1 \beta(p<0.01$, Fig. $3 C)$ and IL-18 ( $p<0.01$, Fig. 3D) in the circulation, as compared to rats in control group.

Iopromide elevated expressions of S100A8/A9, TLR4 and NLRP3 inflammsome in rat CIAKI model

We detected the expression of S100A8/A9 in plasma by ELISA. Fig. 4A revealed that rats in iopromide group showed higher circulatory level of S100A8/A9 than rats in control group $(p<0.01)$. As S100A8/A9 has been recognized as a potent endogenous ligand for TLR4 [14], we further detected the expressions of TLR4 and downstream signal NLRP3 inflammsome. Then immunohistochemistry and western blot analysis were then performed to estimate the expression of TLR4 and NLRP3 inflammasome in renal tissue. TLR4 expression was weak in normal rat kidney. However, kidneys from iopromide group exhibited enhanced expression of TLR4, especially in renal tubule ( $p<0.05$, Fig. 4B). NLRP3 inflammasome consists of three subunits, NLRP3, ASC and Caspase-1. At 24 and $48 \mathrm{~h}$ after iopromide administration, NLAP3, ASC and Caspase- 1 expressions were observed to be obviously increased in the rat kidney $(p<0.01 \sim 0.05$, Fig. 4C-F).

\section{Iopromide induced cell damage in NRK-52E cells}

To further investigate the mechanism underlying the iopromide-induced kidney injury, we performed experiments on rat tubular epithelial cells (NRK-52E cells). In order to test the effect of iopromide on the cell viability in NRK-52E cells, a time-response experiments 


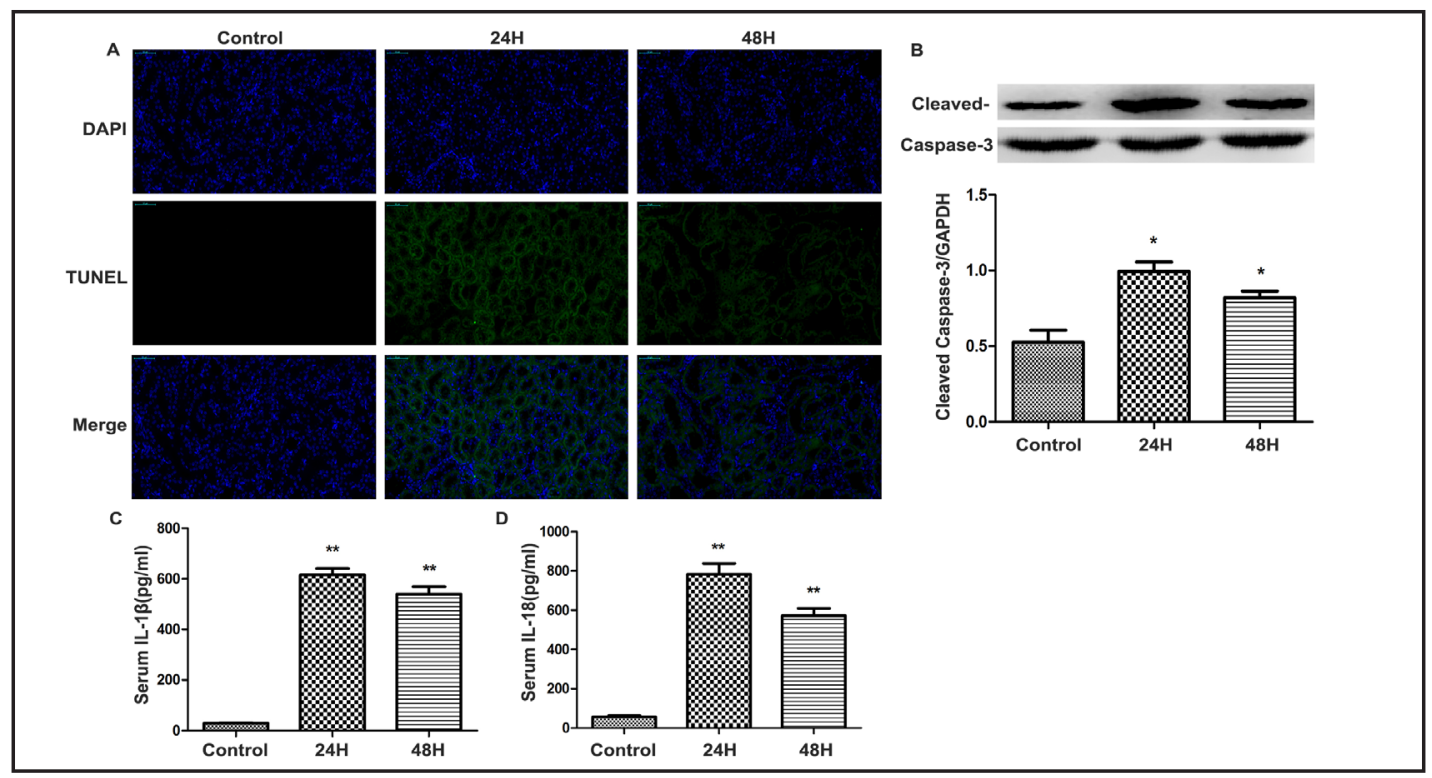

Fig. 3. Iopromide enhanced tubular apoptosis and inflammation in rat CIAKI model. TUNEL staining (A) and detection of renal Caspase-3 expression (B) were used to demonstrate the tubular apoptosis. The concentrations of serum IL-1 $\beta$ (C) and IL-18 (D) were detected to estimate the iopromide induced inflammation. Iopromide remarkably increased the number of TUNEL-positive renal tubular cells at 24 and $48 \mathrm{~h}$ after CM administration. The expression of Caspase- 3 was also elevated by iopromide, with a peak at 24 $\mathrm{h}$ after iopromide injection. Moreover, iopromide enhanced the serum level of IL-1 $\beta$ and IL-18 at $24 \mathrm{~h}$ after $\mathrm{CM}$ treatment, which declined at $48 \mathrm{~h}$ after CM treatment but still significantly higher than control. Data are presented as mean $\pm \mathrm{SD}(\mathrm{n}=6) .{ }^{*} \mathrm{p}<0.05$ vs. control, ${ }^{* *} \mathrm{p}<0.01$ vs. control.

Fig. 4. Iopromide increased expressions of S100A8/A9, TLR4 and NLRP3 inflammsome in rat CIAKI model. The serum concentration of S100A8/A9 (A) was tested by ELISA, while renal expressions of TLR4 (B), NLRP3 (C, D), ASC (C, E) and Caspase-1 (C, F) were estimated by western blot analyses. Iopromide treatment led to profound elevation of S100A8/A9, TLR4, NLRP3, ASC and Caspase- 1 levels at 24 and 48 $\mathrm{h}$ after iopromide injection. Data are presented as mean \pm SD $(n=6)$. ${ }^{*} \mathrm{p}<0.05$ vs. control, ${ }^{* *} \mathrm{p}<0.01$ vs. control.

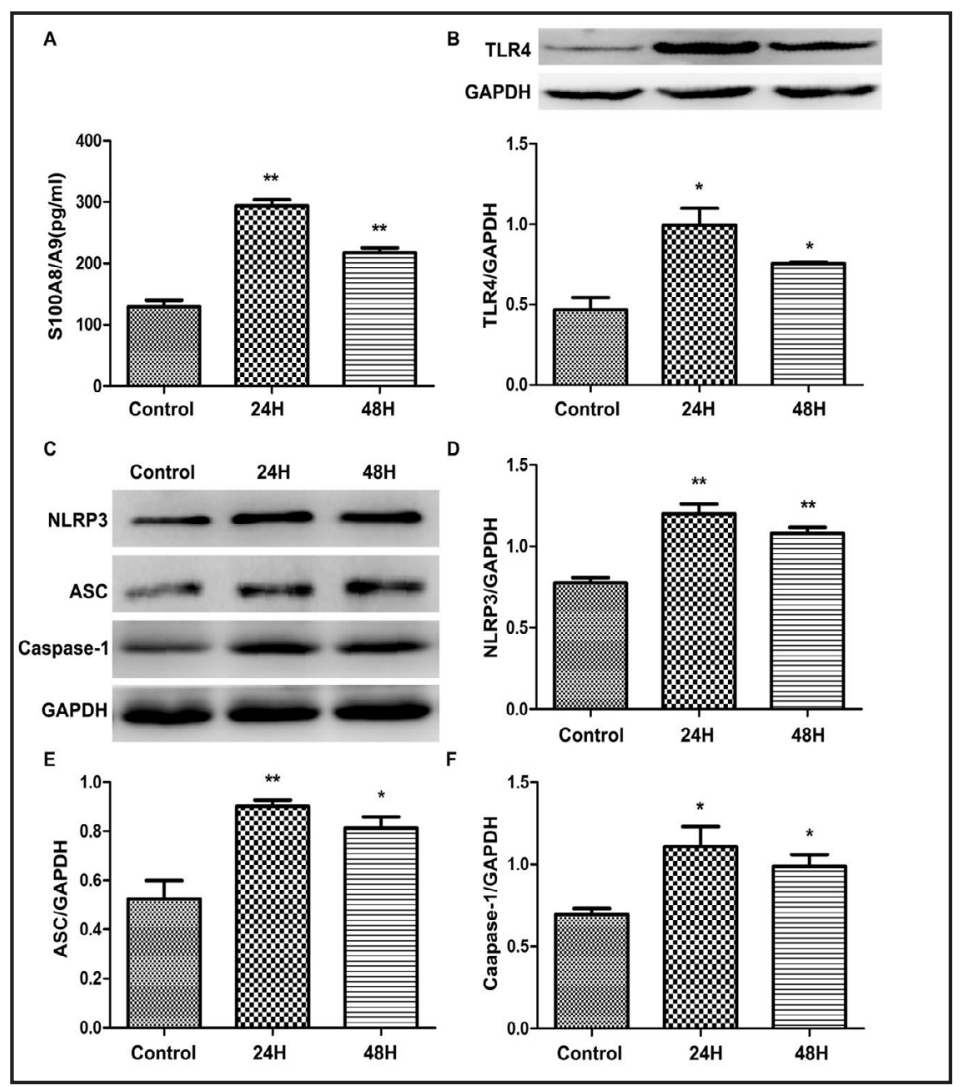




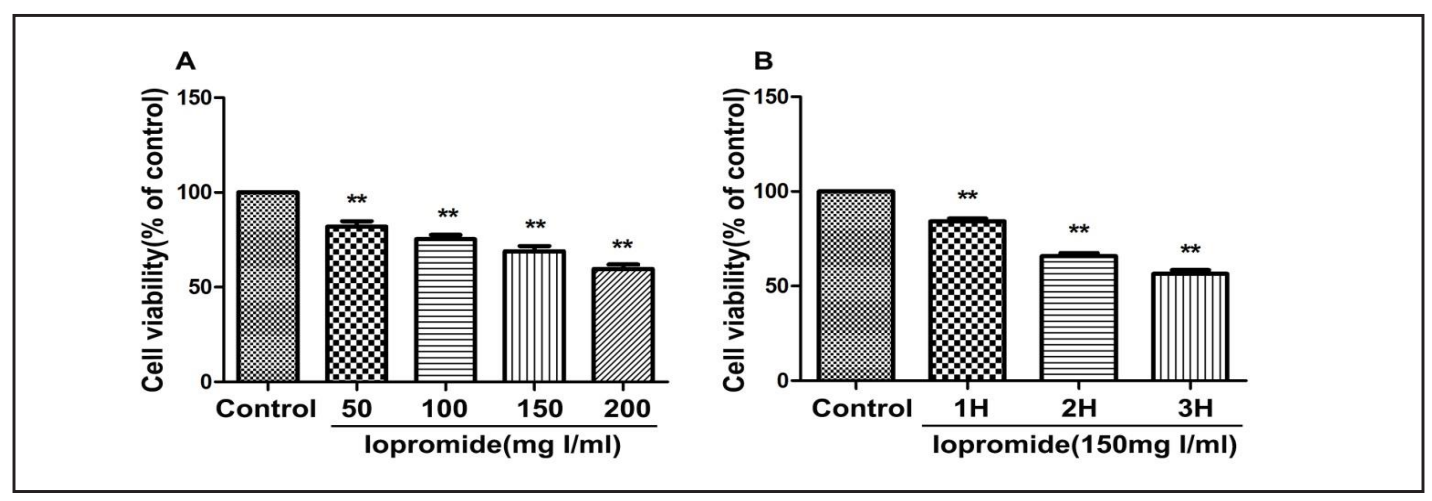

Fig. 5. Iopromide induced cell death in NRK-52E cells in a time-dependent and dose-dependent manner. NRK-52E cells were co-incubated with iopromide in specific concentration (50-150mg I/ml) for $3 \mathrm{~h}$ (A). Cell viability decreased along with CM concentration. Moreover, NRK-52E cells treated with $150 \mathrm{mg} \mathrm{I/ml}$ iopromide showed reduced viability in a time-dependent manner (B). Data are presented as mean \pm SD $(\mathrm{n}=3) .{ }^{* *} \mathrm{p}<0.01$ vs. control.

with indicated time $(1 \mathrm{~h}, 2 \mathrm{~h}, 3 \mathrm{~h})$ and concentration-response experiments with various dose (50,100, 150, $200 \mathrm{mg} \mathrm{I/ml)} \mathrm{were} \mathrm{performed.} \mathrm{As} \mathrm{show} \mathrm{in} \mathrm{Fig.} \mathrm{5A,} \mathrm{cell} \mathrm{viability} \mathrm{decreased}$ with the increasing concentration, which decreased to $70 \%$ at $150 \mathrm{mg} \mathrm{I} / \mathrm{ml}$ compared to the control group. Following exposure of NRK-52E cells to $150 \mathrm{mg} \mathrm{I} / \mathrm{ml}$ iopromide for indicated duration, the destructive effect of iopromide was evident after $1 \mathrm{~h}$ and reached a peak at $3 \mathrm{~h}$ (Fig. 5B). Thus, the NRK-52E cells were processed with $150 \mathrm{mg} \mathrm{I} / \mathrm{ml}$ iopromide for $3 \mathrm{~h}$ in the following experiments.

As illustrated in Fig. 6A, the apoptotic rate determined by Hoechst staining was significantly increased in iopromide treated cells $(p<0.01)$. We also found significant elevation of ROS expression in iopromide-treated NRK-52E cells ( $p<0.01$, Fig. 6B), representing severe cell damage. In addition, iopromide induced inflammation in NRK-52E cells, evidencing by elevated expression of pro-inflammatory cytokines IL- $1 \beta(p<0.05$, Fig. 6C) and IL-18 $(p<0.01$, Fig. 6D). These results were coincident with the in vivo study.

Inhibition of TLR4 alleviated cell damage and NLRP3 inflammasome expression caused by iopromide

Further, we tried to investigate the role of TLR4 in iopromide-induced kidney injury. TAK-242 (inhibitor of TLR4) was co-treated with iopromide for $3 \mathrm{~h}$. Interestingly, inhibition of TLR4 remarkably reduced the iopromide-enhanced apoptotic rate $(p<0.01$, Fig. 6A), ROS generation ( $p<0.01$, Fig. 6B), as well as expression of IL-1 $\beta(p<0.01$, Fig. $6 \mathrm{C})$ and IL-18 $(p<0.05$, Fig. 6D). More importantly, the enhanced expression of NLRP3 was also dampened by co-treatment of TAK-242 ( $p<0.01$, Fig. 7$)$, suggesting TLR4 might act as an upstream signal of NLRP3 inflammasome in iopromide-induced kidney injury. However, TAK-242 alone has no influence on the NRK-52E cells.

NLRP3 inflammasome expression in iopromide-treated NRK-52E cells was suppressed by gene silencing

To clarify whether NLRP3 is also involved in CM-induced kidney injury, we used siRNA to silence NLRP3. The protein level of NLRP3 in NRK-52E cells transfected with NLRP3siRNA was lower than control group ( $p<0.05$, Fig. $8 A)$. Transfection with noncoding RNA didn't cause alteration of the NLRP3 expression (Fig. 8A).

Silencing NLRP3 ameliorated cell damage induced by iopromide

Then we investigated the contribution of NLRP3 inflammsome to iopromide-induced kidney injury. Pretreatment with NLRP3-siRNA for $12 \mathrm{~h}$ before exposure to iopromide 
Fig. 6. Inhibition of TLR4 and silencing NLRP3 could both attenuate iopromide induced apoptosis, ROS generation and inflammation in NRK-52E cells. NRK-52E cells were divided into six groups: control group, CM group (150 mg I/ml iopromide treatment for 3 h), CM+TAK-242 group (co-treatment with $\mathrm{CM}$ and $5 \mu \mathrm{M}$ TAK-242 (inhibitor of TLR4)), CM+NLRP3-siRNA group (CM treatment with pretreatment of NLRP3-siR-


c

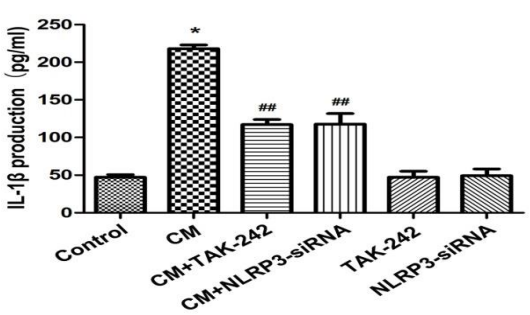

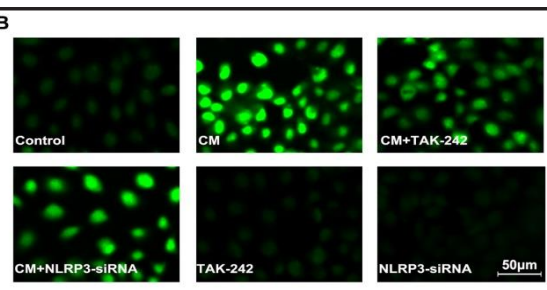

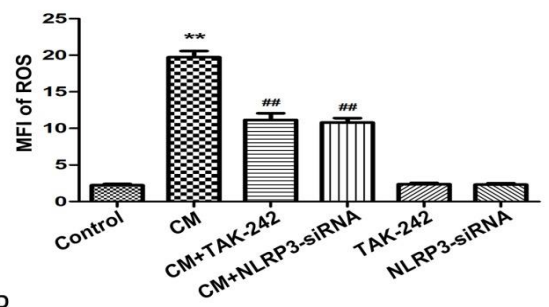

D

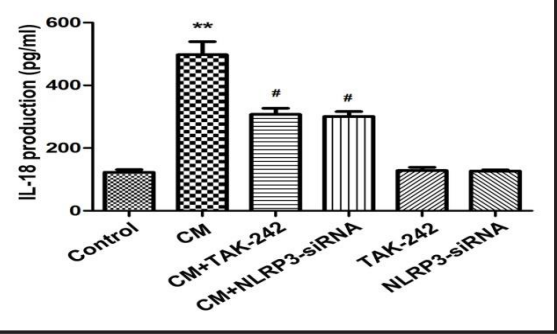

NA), TAK-242 group

( $5 \mu \mathrm{M}$ TAK-242 treatment for $3 \mathrm{~h}$ alone), NLRP3-siRNA group (NLRP3-siRNA treatment alone). Apoptotic rate (A), level of ROS generation (B), and expressions of IL-1 $\beta$ (C) and IL-18 (D) were detected. Iopromide enhanced apoptotic rate, ROS generation and expression of IL-1 $\beta$ and IL-18, which could be significantly ameliorated by TAK-242 and NLRP3-siRNA. TAK-242 and NLRP3-siRNA treatment alone had no effect on NRK-52E cells. Data are presented as mean \pm SD $(n=3)$. ${ }^{*} p<0.05$ vs. control, ${ }^{* *} p<0.01$ vs. control, \#p $<0.05$ vs. CM group, \#\# $\mathrm{p}<0.01$ vs. CM group.

Fig. 7. Inhibition of TLR4 dampened iopromide induced NLRP3 expression in NRK52E cells. $150 \mathrm{mg} \mathrm{I} / \mathrm{ml}$ iopromide treatment for $3 \mathrm{~h}$ caused increased expression of NLRP3 in renal tubular cells. However, co-treatment with TAK-242 could markedly decrease the expression of NLRP3. TAK-242 treatment alone had no effect on NLRP3 expression of NRK-52E cells. Data are presented as mean \pm SD $(n=3) .{ }^{* *} \mathrm{p}<0.01$ vs. control, $\# \# \mathrm{p}<0.01$ vs. CM group.



dramatically reduced the number of apoptotic cells $(p<0.01$, Fig. $6 \mathrm{~A})$ and ROS generation $(p<0.01$, Fig. 6B). The elevated expression of Caspase- 3 induced by iopromide was also attenuated by NLRP3-siRNA pretreatment ( $p<0.01$, Fig. 8B). Likewise, expression of IL-1 $\beta$ $(p<0.01$, Fig. 6C) and IL-18 ( $p<0.05$, Fig. 6D) enhanced by iopromide were concurrently attenuated by NLRP3-siRNA. NLRP3-siRNA alone has no influence on the NRK-52E cells. 


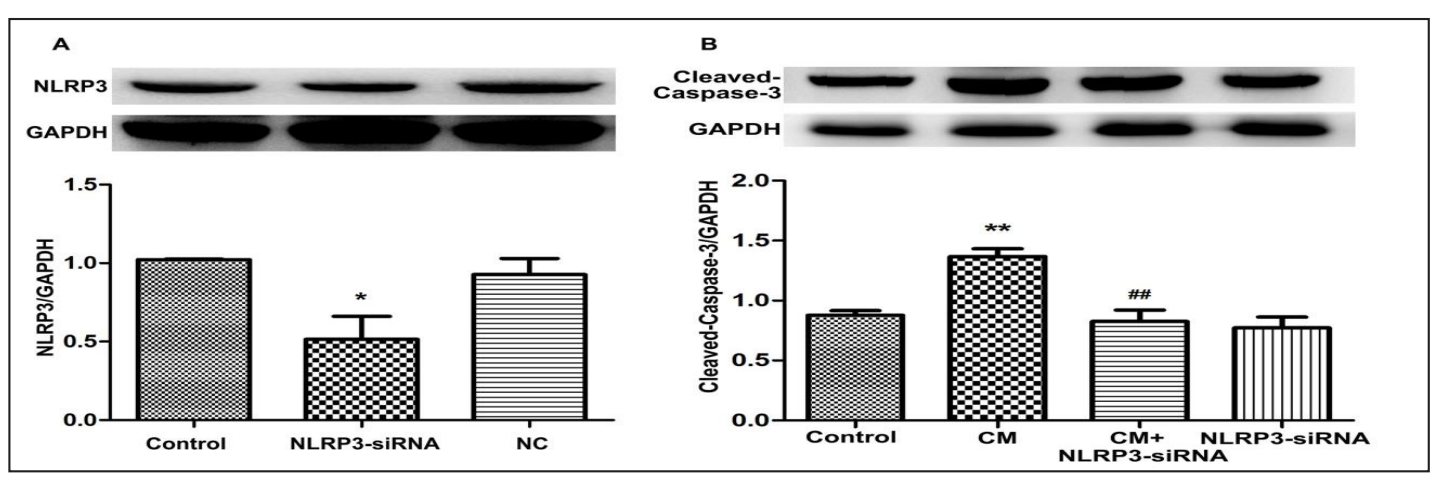

Fig. 8. Silencing NLRP3 ameliorated iopromide induced Caspase-3 expression. NLRP3-siRNA could reduce NLRP3 expression significantly (A), while random noncoding siRNA had no effect on NLRP3 expression. Moreover, co-treatment with iopromide and NLRP3-siRNA led to a considerable decrease in iopromide induced Caspase- 3 expression (B). Data are presented as mean \pm SD ( $n=3) .{ }^{*} p<0.05$ vs. control, ${ }^{* *} \mathrm{p}<0.01$ vs. control, \#\#p<0.01 vs. CM group.

\section{Discussion}

CM is widely applied in radiography and computed tomography, which may cause severe kidney dysfunction particularly in those who have underlying diseases, such as diabetes and pre-existing renal insufficiency. CIAKI is defined as an increase in serum creatinine levels by $\geq 0.5 \mathrm{mg} / \mathrm{dl}$ or by $\geq 25 \%$ above the baseline value within $72 \mathrm{~h}$ of CM injection [7]. In the present study, in order to increase the induction of nephropathy by CM in animals, the combined administration of indomethacin, $\mathrm{N}$ - $\omega$-nitro-Larginine methyl ester (L-NAME), which induced a prolonged reduction of medullary blood flow, and CM was used as previously described [29, $30,32,33]$. We found that rats showed nearly doubled expression of serum creatinine levels at $24 \mathrm{~h}$ after iopromide administration compared to control group, representing successful establishment of CIAKI model. Two other biomarker of renal function, BUN and NGAL, were simultaneously increased. Moreover, $\mathrm{ClCr}$ was reduced by almost $50 \%$ in CIAKI group. Our histopathological studies also confirm significant tubular vacuolar transformation, interstitial edema, and tubular degeneration in CIAKI model. Histologic alterations including proximal tubular vacuolar transformation, interstitial edema, and tubular degeneration following contrast administration have also been reported earlier [34, 35]. Development of edema and enlargement of kidney by CM which was evident by significant increase in Kw/ Bw also confirmed significant renal toxicity.

The mechanisms responsible for the pathogenesis of CIAKI are thought to be a combination of the direct tubular toxicity of contrast media, reduction in medullary blood flow and inflammation [36]. CM can be taken up into the cells and damage mitochondrial function resulting in the increased generation of ROS and cell apoptosis [37, 38]. In our study, we demonstrated significant cell apoptosis, pro-inflammatory cytokine secretion and ROS generation in CM induced renal injury, both by in vivo and in vitro models. According to recent studies, up-regulation of TLR4 expression was reported to be closely correlated with acute kidney injury [19, 39-42]. In acute tubular necrosis, the tubular injury leads to a secondary activation of the innate immune system: TLR4 is constitutively expressed in both proximal and distal tubules, the thin limb of the loop of Henle, and the collecting ducts. Its expression is upregulated in these areas in ischemia reperfusion injury [43]. Cunningham PN et al. elucidated that a decrease in neutrophil infiltration and cell apoptosis was noted in $\mathrm{C} 3 \mathrm{H} / \mathrm{HeJ}$ mice that occur a mutation in TLR4 in LPS-induced ARF [44]. Similar to these studies, our findings validated that CM significantly enhanced the expression of TLR4 both in CIAKI rats and NRK-52E cells. Since activation of TLR4 was validated to be related to different kinds of injuries in various experimental models [45-48], we investigated the role of TLR4 in CM-induced injuries. Increase in the number of apoptotic cells and production of ROS were observed after exposure of cells to CM. However, these injuries induced by CM

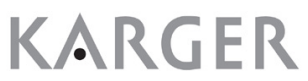




\section{Cellular Physiology Cell Physiol Biochem 2017;43:209-222 \\ \begin{tabular}{ll|l} 
and Biochemistry Published online: August 29, 2017 & $\begin{array}{l}\text { (c) } 2017 \text { The Author(s). Published by S. Karger AG, Basel } \\
\text { www.karger.com/cpb }\end{array}$
\end{tabular}}

were ameliorated intensely by the treatment of TAK-242 (the inhibitor of TLR4), indicating that TLR4 contributed to CM-induced injuries, including apoptosis and ROS generation.

Additionally, the NLRP3 inflammasome was accounted to be associated with multiple inflammatory and autoimmune diseases. Knockout of NLRP3 resulted in the reduction of $\mathrm{NF}-\kappa \mathrm{B}$ activation and cytokine production in Staphylococcus aureus infection [49]. A recent study has found that inflammatory cytokine was strongly depressed in NLRP3-deficient mice of rhabdomyolysis model [21]. According to above studies, we verified the role of NLRP3 inflammasome in CIAKI. Our results showed a significantly increase in the secretion levels of pro-inflammatory, including IL-1 $\beta$ and IL-18 in CI-AKI rats and CM treated NRK-52E cells. Importantly, with the absence of NLRP3, knockout by small interfering RNA, a markedly suppression of IL-1 $\beta$ and IL-18 was observed. Furthermore, in Komada et al's study [21], they showed that the number of apoptotic cell death of CIAKI was markedly decreased by NLRP3 deficiency, indicating NLRP3 inflammasome might be associated with apoptosis. Consistent with their study, we presented that CM-induced injuries, including apoptotic cells and ROS generation were significantly ameliorated with the treatment of siRNA NLRP3.

Simultaneously, we showed a marked elevation of S100A8 and S100A9 expression in plasma of CIAKI rats. S100A8 and S100A9 belong to the family of S100 proteins, which are calcium-binding cytosolic molecules characterized by two calcium-binding EF hands with different affinities for calcium connected by a central hinge region [50]. Circulating levels of S100A8 and S100A9 in healthy subjects range between 0.1 and $0.6 \mathrm{mg} / \mathrm{L}$, and may increase 20 -fold in inflammatory conditions [51,52], which is just coincident with our finding. S100A8 and S100A9 are constitutively expressed by granulocytes, monocytes, and early differentiation stages of macrophages and can be released upon necrosis or actively secreted by phagocytes during inflammation [53, 54]. Upon activation, S100A8 and S100A9 form the S100A8/A9 complex, which translocate to the cytoskeleton and plasma membrane, from which it is secreted $[55,56]$. S100A8/S100A9 could mediate cell death by DNA fragmentation and mitochondrial pathway [50]. Moreover, S100A8/A9 has multiple effects on the NADPH complex. S100A8/A9 transports arachidonic acid, a second messenger in cellular signaling, between the cytosol and the NADPH oxidase complex at the plasma membrane in neutrophils, leading to the oxidative burst important in inflammatory cells [57]. Thus, S100A8/S100A9 is not only a useful marker of inflammation but also plays a pivotal role in the pathogenesis of inflammatory disorders [50]. Similarly, we found increased expression of pro-inflammatory cytokines IL-1 $\beta$ and IL-18, enhanced cell apoptosis and ROS generation and deteriorated renal function paralleling to circulatory S100A8/A9 level, indicating an important role of S100A8/A9 in CIAKI. S100A8/A9 has become widely recognized as a potent endogenous ligand for TLR4 in various diseases including septic shock and vascular and autoimmune disorders [58-60]. In present study, CM induced increased TLR4 expression in both kidney tissue and NRK-52E cells, along with elevation of circulatory S100A8/A9 levels, prompting that CM might activate TLR4 via S100A8/A9, leading to downstream inflammatory cascade and kidney injury.

S100A8/A9 can be used for differentiation between pre-renal AKI and intrinsic AKI [61]. However, there are two potential limitations that have to be discussed. First, the effect of different entities of chronic kidney disease on S100A8/A9 needs further investigation. It appears probable that chronic glomerulonephritis, for example, leads to increased levels of S100A8/A9 independent of a potential acute prerenal deterioration of renal function. Second, urinary tract infection may increase urinary S100A8/A9, because it goes along with leukocyturia. Thus, urinary tract infections with or without coincidental signs of dehydration, being a cause of deteriorating renal function, will be classified as intrarenal AKI.

\section{Conclusion}

We have uncovered for the first time that S100A8/A9 was implicated in CI-AKI by activation of TLR4/NLRP3 inflammasome, which may deepen our knowledge on the mechanism of revealing the pathogenesis of CIAKI. In addition, we provided strong evidence 


\section{Cellular Physiology Cell Physiol Biochem 2017;43:209-222 \begin{tabular}{l|l|l} 
and Biochemistry Published online: August 29, 2017 & $\begin{array}{l}\text { C) } 2017 \text { The Author(s). Published by S. Karger AG, Basel } \\
\text { www.karger.com/cpb }\end{array}$ \\
\hline
\end{tabular} \\ Tan et al.: S100A8/A9 Pathway in CIAKI}

that TLR4/NLRP3 inflammasome contributed to CM-induced injuries in rat kidney, including inflammation, apoptosis and ROS generation. Of note, these results provided new enlightenment that S100A8/A9 and TLR4/NLRP3 inflammasome may be potential therapeutic targets and help us to develop effective prevention strategies.

\section{Disclosure Statement}

All the authors declared no competing interests.

\section{References}

1 Aguiar-Souto P, Ferrante G, Del FF, Barlis P, Khurana R, Di Mario C: Frequency and predictors of contrastinduced nephropathy after angioplasty for chronic total occlusions. Int J Cardiol 2010;139:68-74.

-2 Rich MW, Crecelius CA: Incidence, risk factors, and clinical course of acute renal insufficiency after cardiac catheterization in patients 70 years of age or older. A prospective study. Arch Intern Med 1990;150:12371242.

-3 Goldenberg I, Matetzky S: Nephropathy induced by contrast media: Pathogenesis, risk factors and preventive strategies. CMAJ 2005;172:1461-1471.

4 Jorgensen AL: Contrast-induced nephropathy: Pathophysiology and preventive strategies. Crit Care Nurse 2013;33:37-46.

5 Abe M, Morimoto T, Akao M, Furukawa Y, Nakagawa Y, Shizuta S, Ehara N, Taniguchi R, Doi T, Nishiyama K, Ozasa N, Saito N, Hoshino K, Mitsuoka H, Toma M, Tamura T, Haruna Y, Kita T, Kimura T: Relation of contrast-induced nephropathy to long-term mortality after percutaneous coronary intervention. Am J Cardiol 2014;114:362-368.

6 Luo F, Shi J, Shi Q Xu X, Xia Y, He X: Mitogen-Activated protein kinases and Hypoxic/Ischemic nephropathy. Cell Physiol Biochem 2016;39:1051-1067.

7 Gandhi S, Mosleh W, Abdel-Qadir H, Farkouh ME: Statins and contrast-induced acute kidney injury with coronary angiography. Am J Med 2014;127:987-1000.

8 Brandoni A, Torres AM: Altered renal expression of relevant clinical drug transporters in different models of acute uremia in rats. Role of urea levels. Cell Physiol Biochem 2015;36:907-916.

-9 Lu M, Seufert J, Habener JF: Pancreatic beta-cell-specific repression of insulin gene transcription by CCAAT/ enhancer-binding protein beta. Inhibitory interactions with basic helix-loop-helix transcription factor E47. J Biol Chem 1997;272:28349-28359.

10 Fontes G, Semache M, Hagman DK, Tremblay C, Shah R, Rhodes CJ, Rutter J, Poitout V: Involvement of PerArnt-Sim Kinase and extracellular-regulated kinases-1/2 in palmitate inhibition of insulin gene expression in pancreatic beta-cells. Diabetes 2009;58:2048-2058.

11 Ostermann M, Philips BJ, Forni LG: Clinical review: Biomarkers of acute kidney injury: Where are we now. Crit Care 2012;16:233. doi: 10.1186/cc11380.

12 Fujiu K, Manabe I, Nagai R: Renal collecting duct epithelial cells regulate inflammation in tubulointerstitial damage in mice. J Clin Invest 2011;121:3425-3441.

-13 Dessing MC, Tammaro A, Pulskens WP, Teske GJ, Butter LM, Claessen N, van Eijk M, van der Poll T, Vogl T, Roth J, Florquin S, Leemans JC: The calcium-binding protein complex S100A8/A9 has a crucial role in controlling macrophage-mediated renal repair following ischemia/reperfusion. Kidney Int 2015;87:85-94.

14 Vogl T, Tenbrock K, Ludwig S, Leukert N, Ehrhardt C, van Zoelen MA, Nacken W, Foell D, van der Poll T, Sorg C, Roth J: Mrp8 and Mrp14 are endogenous activators of Toll-like receptor 4, promoting lethal, endotoxininduced shock. Nat Med 2007;13:1042-1049.

15 Frangogiannis NG: The inflammatory response in myocardial injury, repair, and remodelling. Nat Rev Cardiol 2014;11:255-265.

16 Feng Y, Yang S, Ma Y, Bai XY, Chen X: Role of Toll-like receptors in diabetic renal lesions in a miniature pig model. Sci Adv 2015;1:e1400183.

17 Qi M, Zheng L, Qi Y, Han X, Xu Y, Xu L, Yin L, Wang C, Zhao Y, Sun H, Liu K, Peng J: Dioscin attenuates renal ischemia/reperfusion injury by inhibiting the TLR4/MyD88 signaling pathway via up-regulation of HSP70. Pharmacol Res 2015;100:341-352. 


\section{Cellular Physiology Cell Physiol Biochem 2017;43:209-222 \begin{tabular}{ll|l} 
and Biochemistry Published onlıne: August 29, 2017 & $\begin{array}{l}\text { (c) } 2017 \text { The Author(s). Published by S. Karger AG, Basel } \\
\text { www.karger.com/cpb }\end{array}$
\end{tabular}}

18 Bergler T, Hoffmann U, Bergler E, Jung B, Banas MC, Reinhold SW, Kramer BK, Banas B: Toll-like receptor 4 in experimental kidney transplantation: Early mediator of endogenous danger signals. Nephron Exp Nephrol 2012;121:e59-e70.

19 Wu H, Chen G, Wyburn KR, Yin J, Bertolino P, Eris JM, Alexander SI, Sharland AF, Chadban SJ: TLR4 activation mediates kidney ischemia/reperfusion injury. J Clin Invest 2007;117:2847-2859.

20 Duewell P, Kono H, Rayner KJ, Sirois CM, Vladimer G, Bauernfeind FG, Abela GS, Franchi L, Nunez G, Schnurr M, Espevik T, Lien E, Fitzgerald KA, Rock KL, Moore KJ, Wright SD, Hornung V, Latz E: NLRP3 inflammasomes are required for atherogenesis and activated by cholesterol crystals. Nature 2010;464:1357-1361.

21 Komada T, Usui F, Kawashima A, Kimura H, Karasawa T, Inoue Y, Kobayashi M, Mizushina Y, Kasahara T, Taniguchi S, Muto S, Nagata D, Takahashi M: Role of NLRP3 inflammasomes for rhabdomyolysis-induced acute kidney injury. Sci Rep 2015;5:10901.

-22 Iyer SS, Pulskens WP, Sadler JJ, Butter LM, Teske GJ, Ulland TK, Eisenbarth SC, Florquin S, Flavell RA, Leemans JC, Sutterwala FS: Necrotic cells trigger a sterile inflammatory response through the Nlrp3 inflammasome. Proc Natl Acad Sci U S A 2009;106:20388-20393.

23 Chunzhi G, Zunfeng L, Chengwei Q, Xiangmei B, Jingui Y: Hyperin protects against LPS-induced acute kidney injury by inhibiting TLR4 and NLRP3 signaling pathways. Oncotarget 2016;7:82602-82608.

24 Martin-Rodriguez S, Caballo C, Gutierrez G, Vera M, Cruzado JM, Cases A, Escolar G, Diaz-Ricart M: TLR4 and NALP3 inflammasome in the development of endothelial dysfunction in uraemia. Eur J Clin Invest 2015;45:160-169.

25 Yang Y, Zhang DM, Liu JH, Hu LS, Xue QC, Ding XQ, Kong LD: Wuling San protects kidney dysfunction by inhibiting renal TLR4/MyD88 signaling and NLRP3 inflammasome activation in high fructose-induced hyperuricemic mice. J Ethnopharmacol 2015;169:49-59.

26 Hosseinian N, Cho Y, Lockey RF, Kolliputi N: The role of the NLRP3 inflammasome in pulmonary diseases. Ther Adv Respir Dis 2015;9:188-197.

27 Toldo S, Mezzaroma E, Mauro AG, Salloum F, Van Tassell BW, Abbate A: The inflammasome in myocardial injury and cardiac remodeling. Antioxid Redox Signal 2015;22:1146-1161.

-28 Turner CM, Arulkumaran N, Singer M, Unwin RJ, Tam FW: Is the inflammasome a potential therapeutic target in renal disease? BMC Nephrol 2014;15:21.

29 Agmon Y, Peleg H, Greenfeld Z, Rosen S, Brezis M: Nitric oxide and prostanoids protect the renal outer medulla from radiocontrast toxicity in the rat. J Clin Invest 1994;94:1069-1075.

30 Goldfarb M, Rosenberger C, Ahuva S, Rosen S, Heyman SN: A role for erythropoietin in the attenuation of radiocontrast-induced acute renal failure in rats. Ren Fail 2006;28:345-350.

-31 Weidemann A, Bernhardt WM, Klanke B, Daniel C, Buchholz B, Campean V, Amann K, Warnecke C, Wiesener MS, Eckardt KU, Willam C: HIF activation protects from acute kidney injury. J Am Soc Nephrol 2008;19:486494.

-32 Vari RC, Natarajan LA, Whitescarver SA, Jackson BA, Ott CE: Induction, prevention and mechanisms of contrast media-induced acute renal failure. Kidney Int 1988;33:699-707.

-33 Yokomaku Y, Sugimoto T, Kume S, Araki S, Isshiki K, Chin-Kanasaki M, Sakaguchi M, Nitta N, Haneda M, Koya D, Uzu T, Kashiwagi A: Asialoerythropoietin prevents contrast-induced nephropathy. J Am Soc Nephrol 2008;19:321-328.

34 Berns AS: Nephrotoxicity of contrast media. Kidney Int 1989;36:730-740.

35 Guan X, Qian Y, Shen Y, Zhang L, Du Y, Dai H, Qian J, Yan Y: Autophagy protects renal tubular cells against ischemia / reperfusion injury in a time-dependent manner. Cell Physiol Biochem 2015;36:285-298.

-36 Solomon R, Dauerman HL: Contrast-induced acute kidney injury. Circulation 2010;122:2451-2455.

37 Persson PB, Hansell P, Liss P: Pathophysiology of contrast medium-induced nephropathy. Kidney Int 2005;68:14-22.

38 Yuan Y, Wang H, Wu Y, Zhang B, Wang N, Mao H, Xing C: P53 contributes to cisplatin induced renal oxidative damage via regulating p66shc and MnSOD. Cell Physiol Biochem 2015;37:1240-1256.

-39 Pulskens WP, Teske GJ, Butter LM, Roelofs JJ, van der Poll T, Florquin S, Leemans JC: Toll-like receptor-4 coordinates the innate immune response of the kidney to renal ischemia/reperfusion injury. PLoS One 2008;3:e3596.

-40 Chen J, John R, Richardson JA, Shelton JM, Zhou XJ, Wang Y, Wu QQ, Hartono JR, Winterberg PD, Lu CY: Toll-like receptor 4 regulates early endothelial activation during ischemic acute kidney injury. Kidney Int 2011;79:288-299. 


\section{Cellular Physiology Cell Physiol Biochem 2017;43:209-222 \begin{tabular}{ll|l} 
and Biochemistry Published online: August 29, 2017 & $\begin{array}{l}\text { (C) } 2017 \text { The Author(s). Published by S. Karger AG, Basel } \\
\text { www.karger.com/cpb }\end{array}$
\end{tabular}}

41 Li Y, Zhong D, Lei L, Jia Y, Zhou H, Yang B: Propofol prevents renal Ischemia-Reperfusion injury via inhibiting the oxidative stress pathways. Cell Physiol Biochem 2015;37:14-26.

-42 Preising C, Schneider R, Bucher M, Gekle M, Sauvant C: Regulation of expression of renal organic anion transporters OAT1 and OAT3 in a model of Ischemia/Reperfusion injury. Cell Physiol Biochem 2015;37:113.

$\$ 43$ Wolfs TG, Buurman WA, van Schadewijk A, de Vries B, Daemen MA, Hiemstra PS, van T VC: In vivo expression of Toll-like receptor 2 and 4 by renal epithelial cells: IFN-gamma and TNF-alpha mediated upregulation during inflammation. J Immunol 2002;168:1286-1293.

44 Cunningham PN, Wang Y, Guo R, He G, Quigg RJ: Role of Toll-like receptor 4 in endotoxin-induced acute renal failure. J Immunol 2004;172:2629-2635.

45 Tsuboi N, Yoshikai Y, Matsuo S, Kikuchi T, Iwami K, Nagai Y, Takeuchi O, Akira S, Matsuguchi T: Roles of tolllike receptors in C-C chemokine production by renal tubular epithelial cells. J Immunol 2002;169:20262033.

46 Gay NJ, Gangloff M: Structure and function of Toll receptors and their ligands. Annu Rev Biochem 2007;76:141-165.

47 Doi K, Ishizu T, Tsukamoto-Sumida M, Hiruma T, Yamashita T, Ogasawara E, Hamasaki Y, Yahagi N, Nangaku M, Noiri E: The high-mobility group protein B1-Toll-like receptor 4 pathway contributes to the acute lung injury induced by bilateral nephrectomy. Kidney Int 2014;86:316-326.

-48 Wang Y, Chen G, Yu X, Li Y, Zhang L, He Z, Zhang N, Yang X, Zhao Y, Li N, Qiu H: Salvianolic acid b ameliorates cerebral Ischemia/Reperfusion injury through inhibiting TLR4/MyD88 signaling pathway. Inflammation 2016;39:1503-1513.

49 Kinoshita T, Imamura R, Kushiyama H, Suda T: NLRP3 mediates NF-kappaB activation and cytokine induction in microbially induced and sterile inflammation. PLoS One 2015;10:e119179.

-50 Ehrchen JM, Sunderkotter C, Foell D, Vogl T, Roth J: The endogenous Toll-like receptor 4 agonist S100A8/ S100A9 (calprotectin) as innate amplifier of infection, autoimmunity, and cancer. J Leukocyte Biol 2009;86:557-566.

51 Strasser F, Gowland PL, Ruef C: Elevated serum macrophage inhibitory factor-related protein (MRP) 8/14 levels in advanced HIV infection and during disease exacerbation. J Acquir Immune Defic Syndr Hum Retrovirol 1997;16:230-238.

52 Schulze ZWA, Foell D, Frosch M, Vogl T, Sorg C, Roth J: Myeloid related proteins MRP8/MRP14 may predict disease flares in juvenile idiopathic arthritis. Clin Exp Rheumatol 2004;22:368-373.

53 Foell D, Wittkowski H, Vogl T, Roth J: S100 proteins expressed in phagocytes: A novel group of damageassociated molecular pattern molecules. J Leukoc Biol 2007;81:28-37.

54 Ehrchen JM, Sunderkotter C, Foell D, Vogl T, Roth J: The endogenous Toll-like receptor 4 agonist S100A8/S100A9 (calprotectin) as innate amplifier of infection, autoimmunity, and cancer. J Leukoc Biol 2009;86:557-566.

-55 Teigelkamp S, Bhardwaj RS, Roth J, Meinardus-Hager G, Karas M, Sorg C: Calcium-dependent complex assembly of the myeloic differentiation proteins MRP-8 and MRP-14. J Biol Chem 1991;266:13462-13467.

56 Rammes A, Roth J, Goebeler M, Klempt M, Hartmann M, Sorg C: Myeloid-related protein (MRP) 8 and MRP14, calcium-binding proteins of the S100 family, are secreted by activated monocytes via a novel, tubulin-dependent pathway. J Biol Chem 1997;272:9496-9502.

57 Kerkhoff C, Nacken W, Benedyk M, Dagher MC, Sopalla C, Doussiere J: The arachidonic acid-binding protein S100A8/A9 promotes NADPH oxidase activation by interaction with p67phox and Rac-2. Faseb J 2005;19:467-469.

58 Vogl T, Tenbrock K, Ludwig S, Leukert N, Ehrhardt C, van Zoelen MA, Nacken W, Foell D, van der Poll T, Sorg C, Roth J: Mrp8 and Mrp14 are endogenous activators of Toll-like receptor 4, promoting lethal, endotoxininduced shock. Nat Med 2007;13:1042-1049.

59 Croce K, Gao H, Wang Y, Mooroka T, Sakuma M, Shi C, Sukhova GK, Packard RR, Hogg N, Libby P, Simon DI: Myeloid-related protein-8/14 is critical for the biological response to vascular injury. Circulation 2009;120:427-436.

60 Loser K, Vogl T, Voskort M, Lueken A, Kupas V, Nacken W, Klenner L, Kuhn A, Foell D, Sorokin L, Luger TA, Roth J, Beissert S: The Toll-like receptor 4 ligands Mrp8 and Mrp14 are crucial in the development of autoreactive CD8+ T cells. Nat Med 2010;16:713-717.

61 Heller F, Frischmann S, Grunbaum M, Zidek W, Westhoff TH: Urinary calprotectin and the distinction between prerenal and intrinsic acute kidney injury. Clin J Am Soc Nephrol 2011;6:2347-2355. 